\title{
Acceptability of an Interactive Computer-Animated Agent to Promote Patient-Provider Communication About Breast Density: a Mixed Method Pilot Study
}

\author{
Christine Gunn, $P h D^{7}$ D, Ariel Maschke, $M A^{7}$, Timothy Bickmore, $P h D^{2}$, \\ Mark Kennedy, MBA ${ }^{3}$, Margaret F. Hopkins, $\mathrm{MPH}^{4}$, Michael D.C. Fishman, MD ${ }^{5}$, \\ Michael K. Paasche-Orlow, MD, MPH', and Erica T. Warner, ScD, MPH ${ }^{4}$
}

\begin{abstract}
'Department of Medicine, Section of General Internal Medicine, Women's Health Unit, Boston University School of Medicine, Boston, MA, USA; ${ }^{2}$ Khoury College of Computer Sciences, Northeastern University, Boston, USA; ${ }^{3}$ Boston Public Health Commission, Boston, USA; ${ }^{4}$ Department of Medicine, Massachusetts General Hospital, Boston, USA; ${ }^{5}$ Department of Radiology, Boston Medical Center, Section of Breast Imaging, Boston University School of Medicine, Boston, USA; ${ }^{\circ}$ Department of Medicine, Section of General Internal Medicine, Boston Medical Center, Boston University School of Medicine, Boston, USA.
\end{abstract}

BACKGROUND: Half of women undergoing mammography have dense breasts. Mandatory dense breast notification and educational materials have been shown to confuse women, rather than empower them.

OBJECTIVE: This study used a mixed method, multistakeholder approach to assess acceptability of an interactive, computer-animated agent that provided breast density information to women and changes in knowledge, satisfaction, and informational needs.

DESIGN: A pre-post survey and qualitative focus groups assessed the acceptability of the computer-animated agent among women. An anonymous, online survey measuring acceptability was delivered to a multi-stakeholder group.

PARTICIPANTS: English-speaking, mammographyeligible women ages 40-74 were invited and 44 women participated in one of nine focus groups. In addition, 14 stakeholders representing primary care, radiology, patient advocates, public health practitioners, and researchers completed the online survey.

INTERVENTIONS: A prototype of a computer-animated agent was delivered to women in a group setting; stakeholders viewed the prototype independently.

MAIN MEASURES: Data collected included open-ended qualitative questions that guided discussion about the content and form of the computer-animated agent. Structured surveys included domains related to knowledge, acceptability, and satisfaction. Stakeholder acceptability was measured with a series of statements about aspects of the intervention and delivery approach and are reported as the proportion of respondents who endorsed each statement.

KEY RESULTS: Six of 12 knowledge items demonstrated improvement post-intervention, satisfaction with the agent was high $(81 \%)$, but the number of unanswered

Prior Presentations: Preliminary results were previously presented at the International Breast Density and Cancer Risk Assessment Workshop on June 6, 2019, in Honolulu, Hawaii, and at the Society for General Internal Medicine Annual Meeting on May 9, 2019, in Washington D.C.

Received September 12, 2019

Accepted December 13, 2019

Published online January 9, 2020 questions did not improve (67\% vs. $54 \%, p=0.37$ ). Understanding of the distinction between connective and fatty tissue in the breast did not increase (30\% vs. $26 \%, p=$ 0.48). Results of the multi-stakeholder survey suggest broad acceptability of the approach and agent.

CONCLUSIONS: Findings highlight the benefits of a brief interactive educational exposure as well as misperceptions that persisted. Results demonstrate the need for an evidence-based, accessible intervention that is easy to understand for patients.

KEY WORDS: breast density; mammography; acceptability; health information technology; patient-provider communication.

J Gen Intern Med 35(4):1069-77

DOI: $10.1007 / \mathrm{s} 11606-019-05622-2$

(c) Society of General Internal Medicine 2020

\section{BACKGROUND}

Over 27 million women in the USA have mammographically dense breasts, representing $40-50 \%$ of women undergoing mammography. ${ }^{1}$ Women with heterogeneously or extremely dense breasts are at 1.2-2.3 times greater risk of breast cancer compared to women with scattered fibroglandular density. ${ }^{2}$ Dense breasts are associated with higher rates of interval cancers, ${ }^{3}$ those identified between routine screenings, in part due to reduced mammography sensitivity. ${ }^{4}$ Breast density also varies by race, with black women more likely to have high breast density. ${ }^{5}$ Over 36 states have passed laws requiring that women receive written notification of their breast density postmammogram, ${ }^{6}$ and the FDA has proposed regulations to set a national dense breast reporting standard. ${ }^{7}$ Currently, mandated dense breast notification content and its complexity varies by state. ${ }^{8}$ Notifications are intended to increase individual awareness of risk and support informed decision-making for supplemental screening, but early indications are that these laws do not fulfill this potential. Many women feel confused or anxious after receiving notifications, gain little knowledge, and are not clear on what to do based on notifications. ${ }^{9-12}$ 
The balance of risks and benefits of supplemental screening among women with high density remains unclear. ${ }^{13}$ As evidence on appropriate screening for women with dense breasts accrues, many recommend situating breast density within the context of overall breast cancer risk to determine need for supplemental screening. ${ }^{14,}{ }^{15}$ Yet, primary care providers feel ill-prepared to counsel women about dense breasts and few report using risk assessment tools to determine appropriate supplemental screening, ${ }^{16-18}$ despite available guidance on risk stratification for women with dense breasts to inform choices. ${ }^{14,15,19}$ Thus, awareness of breast density and associated risks remains low. ${ }^{9,20-24}$

Improvements in communication and education are needed for both patients and providers, but the field has yet to rigorously develop educational tools that address known misperceptions. Our previous work shows women want to be told of their breast density and require more information to make informed decisions. $^{12,25}$ This study aimed to (1) develop a prototype interactive tool for patients to supplement breast density notifications using a community-engaged approach; (2) test the impact of the prototype on breast density knowledge, informational needs, and satisfaction among a mammography-eligible women; and (3) assess acceptability among a multi-stakeholder group including patients, public health professionals, and providers from primary care and radiology.

\section{METHODS}

Overview. This cross-sectional study assessed acceptability and changes in knowledge with the use of an interactive, computer-animated agent that provided breast density information. We used surveys and qualitative focus groups to evaluate the agent developed in partnership with a local breast cancer advocacy group. Data collection occurred from April through June 2019. This research was reviewed and approved by the Boston Medical Center Institutional Review Board.

Educational Material Development. We aimed to develop materials that would address the known knowledge gaps in breast density notifications and be focused on user needs. We sought to include minority women in the development, as minority women are less often aware of breast density, ${ }^{26}$ yet are more likely to have dense breasts ${ }^{5}$ and experience poorer cancer outcomes. $^{27,28}$ Thus, we partnered with the Pink and Black Education and Support Network, a group of black breast cancer survivors who lead education and outreach efforts. We held two facilitated feedback sessions with Pink and Black members $(n=10)$ during which we identified their top priorities for breast density education using a cognitive priming task. Women rated a series of statements and their relative importance. Their highest stated priorities included (1) knowing what they could do about dense breasts, (2) being able to ask questions, and (3) getting information quickly.
Based on prior work developing conversational agent systems that are responsive to patient health information needs, ${ }^{29-}$ 32 we created a prototype computer-animated agent that simulates a face-to-face conversation with a health educator (Fig. 1). Computer-animated agents address women's desire for accessibility and interactivity as they adapt messages to individual patient responses and the immediate context of the conversation. They also provide information in a consistent manner and in a low-pressure environment, outside of the time-constrained clinical encounter, so that patients may take as much time as they need to fully understand the information. ${ }^{33}$ The information in the current prototype was adapted from patient educational materials on breast density, and modeled into a conversational, interactive form. Salient topics and descriptions were identified as desirable by Pink and Black Education and Support Network members who provided feedback prior to prototype development. ${ }^{34,35}$

The prototype, Danya, was presented to women through two sample interactions displayed as videos: a 30-s greeting introduced Danya as a virtual health counselor and a 3-min sample in which Danya presented information about breast density. The sample interaction reviewed when women could expect results, displayed a sample breast density notification letter, reassured women, explained breast density using pictures, and described some possible next steps. Both videos included demonstrations of Danya's interactive elements, with an off-screen user providing responses to Danya's prompts.

Study Population. We tested the prototype among 44 mammography-eligible English-speaking women ages 4074. Study information cards and flyers were posted in primary care and radiology clinics, as well as distributed by Pink and Black advocates within community venues. Interested participants contacted the study team, who verified eligibility and scheduled women into one of nine focus groups. Additionally, stakeholders representing primary care clinicians, radiologists, patient advocates, public health practitioners, and researchers were identified through the authors' professional networks. Stakeholders received an email invitation to view the online prototype and complete a survey about the content.

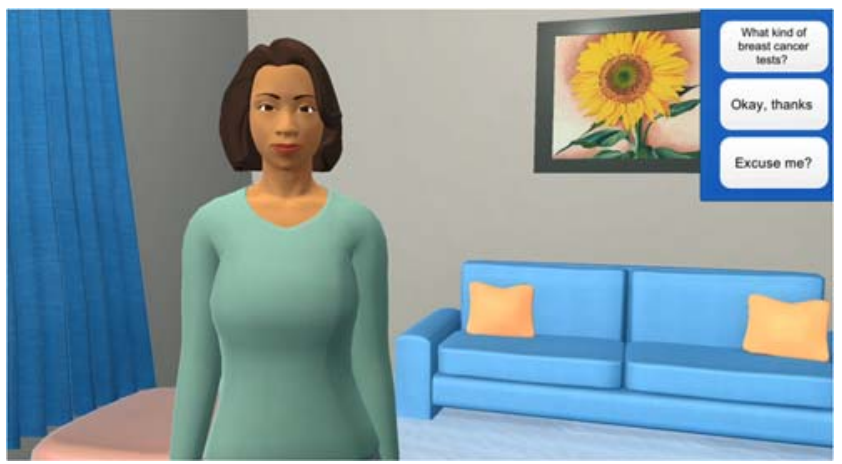

Figure 1 Screenshot of prototype computer-animated agent, Danya. 
Focus Group Data Collection. Data from mammographyeligible women was collected through 90-120 min focus groups with associated surveys administered before and after exposure to the computer-animated agent. Study activities took place at Boston Medical Center or community centers. Upon arrival, women reviewed a study information sheet and completed a baseline survey covering knowledge about breast density, mammogram history, satisfaction with information related to mammogram results, and demographics. All women agreed to audio-recording of the focus group, which was later transcribed. Focus groups were facilitated by an investigator, with at least one research assistant taking notes. Facilitators presented the computer-animated agent 30-s greeting and elicited impressions about the style and substance. The 3min breast density education clip was then shown, again followed by guided discussion about the content and form. After conclusion of the focus group, women completed a second survey covering knowledge about breast density, and satisfaction. Women received a $\$ 40$ debit card for their participation at the conclusion of study activities.

Multi-stakeholder Data Collection. Surveys measuring acceptability of the agent and delivery strategy were collected online. Stakeholders were invited by email to review the computer-animated agent prototype and provide feedback via a structured survey. Data were collected and managed using REDCap (Research Electronic Data Capture) hosted at Boston University, CTSI UL1TR001430. ${ }^{36}$

Measures. Data collected from mammography-eligible women included open-ended qualitative questions that guided discussion about the content and form of the computer-animated agent. Structured surveys included domains related to knowledge, acceptability, and satisfaction. Three scales were compared pre-post: (1) Knowledge, measured by 12 true/false statements about key information in the breast density video; (2) Unmet informational needs comprised of three items, measuring women's satisfaction with the level and amount of information and whether there were remaining questions; (3) Satisfaction, measured on a 5-point Likert scale (Very Satisfied to Very Dissatisfied). We hypothesized that the computer-animated agent would increase knowledge and satisfaction, while decreasing unmet informational needs.

The online stakeholder surveys included an initial question to determine whether the respondent was a clinical provider, which determined branching logic. All respondents were asked about acceptability either for themselves (nonclinicians) or their patients (clinician stakeholders) related to the computer-animated agent and delivery approach. Measures are reported as percent agreement for each statement.

Analysis. Qualitative analysis included creating a taxonomy of potential issues related to the prototype's content, context, and format that guided analysis ${ }^{37}$ using NVivo qualitative software. One author primarily coded transcripts to develop a codebook and reviewed it with the study team. Using constant comparison techniques, ${ }^{38}$ we ensured that fidelity was maintained by having a second author review coded transcripts to ensure transparency and quality in coding. Any clarifications in coding were resolved through study team discussion.

Descriptive statistics (means, medians, frequencies) were generated for each of the survey measures of satisfaction, informational needs, and breast density knowledge. Pre-post comparisons using McNemar's tests with an exact function to account for small cell sizes, explored pre-post changes in satisfaction, informational needs, and knowledge. Statistical significance was set at the level of $p<0.05$. Stakeholder surveys descriptively summarized acceptability for all stakeholder groups.

\section{RESULTS}

Focus Group Participant Characteristics. As displayed in Table 1, focus group participants had a mean age of 59 years $(\mathrm{SD}=7.7)$ and were predominantly black $(73 \%, n=32)$. Educational backgrounds were diverse with $14 \%(n=6)$ completing less than high school, 34\% $(n=15)$ with a high school degree or GED, 20\% ( $n=9)$ attended some college, and 32\% had an Associate's degree or higher. Most women were either very $(57 \%, n=25)$ or somewhat $(23 \%, n=10)$ satisfied with the mammogram results information they had received in the past, although focus groups later uncovered uncertainty and confusion about mammography concepts. One-third of participants $(32 \%, n=14)$ reported they had been told they have dense breasts; one-quarter were unsure $(25 \%, n=11)$. When asked about sources of breast density information, the most common response was that they had received no breast density information ( $45 \%, n=20$ ), followed by receiving information from a primary care doctor $(30 \%, n=13)$.

Focus Group Results. As displayed in Table 2, most participants reported they were satisfied with the computer-animated agent, Danya $(68 \%, n=30)$, she was easy to understand $(75 \%$, $n=33)$, they were confident in her ability to help them $(64 \%$, $n=28)$, and would follow her advice $(55 \%, n=24)$. Half felt comfortable with Danya or would like to continue working with her $(50 \%, n=22)$. Additionally, Danya made $40 \%$ ( $n=$ 18 ) of participants less nervous about dense breasts. Women described experiencing heightened anxiety while awaiting results, and felt Danya could support them in this period: "You will panic if you don't hear from them, 'Oh, it's been a week.' So for her to be able to give [women] that information, I definitely think that was good." Women were split in expressing strong preferences for communication with a doctor or nurse over the computer-animated agent: $57 \%(n=25)$ 
Table 1 Characteristics of Focus Group Participants $(N=44)$

\begin{tabular}{|c|c|}
\hline Variable & Mean (SD) \\
\hline Age & $\begin{array}{l}59.0(8) \\
\text { Frequency }(\%)\end{array}$ \\
\hline \multicolumn{2}{|l|}{ Race/ethnicity } \\
\hline Non-Hispanic White & $6(14)$ \\
\hline Black & $32(73)$ \\
\hline Hispanic White & $2(5)$ \\
\hline Other & $1(2)$ \\
\hline Declined & $3(7)$ \\
\hline \multicolumn{2}{|l|}{ Education } \\
\hline$<$ High school & $6(14)$ \\
\hline High school/GED & $15(34)$ \\
\hline Some college, no degree & $9(20)$ \\
\hline Associate & $7(16)$ \\
\hline Bachelor's & $3(7)$ \\
\hline Masters & $4(9)$ \\
\hline \multicolumn{2}{|c|}{$\begin{array}{l}\text { Satisfaction with mammogram results } \\
\text { information (pre-intervention) }\end{array}$} \\
\hline Very satisfied & $25(57)$ \\
\hline Somewhat satisfied & $10(23)$ \\
\hline Neutral & $6(14)$ \\
\hline Somewhat dissatisfied & $1(2)$ \\
\hline Very dissatisfied & $1(2)$ \\
\hline Missing & $1(2)$ \\
\hline \multicolumn{2}{|l|}{ Told has dense breasts } \\
\hline Yes & $14(32)$ \\
\hline No & $16(36)$ \\
\hline Unsure & $11(25)$ \\
\hline Missing & $3(7)$ \\
\hline \multicolumn{2}{|c|}{ Breast density information sources ${ }^{1}$} \\
\hline No information obtained & $20(45)$ \\
\hline Primary care doctor & $13(30)$ \\
\hline Notification letter & $5(11)$ \\
\hline Radiologist & $1(2)$ \\
\hline Breast technician & $8(18)$ \\
\hline Internet & $1(2)$ \\
\hline Friends/family & $3(7)$ \\
\hline
\end{tabular}

${ }^{I}$ Percentages do not add to 100 because participants could select multiple responses

strongly agreed or agreed with the statement "I would rather talk to my doctor than Danya," while $43 \%(n=19)$ did so for a similar statement about their nurse. One theme that emerged was a preference for being able to ask questions from a credible source without judgment, a need many women felt Danya could meet: "[Danya] would be good because maybe

Table 2 Evaluation of Computer-Animated Agent (Danya), \% Endorsement

\begin{tabular}{ll}
\hline \hline Statement & $\begin{array}{l}\text { Endorsement } \\
\text { N }\end{array}$ \\
\hline Danya was easy to understand & $33(75)$ \\
I was satisfied with Danya & $30(68)$ \\
I am confident in Danya's ability to help me & $28(64)$ \\
I would follow Danya's advice & $24(55)$ \\
I feel comfortable with Danya & $22(50)$ \\
I would like to continue working with Danya & $22(50)$ \\
Danya cares about me & $19(43)$ \\
Danya made me feel less nervous about dense & $18(40)$ \\
breasts & $16(36)$ \\
I trust Danya & $15(34)$ \\
Danya was repetitive & $7(16)$ \\
I would rather talk to my nurse than Danya & $5(11)$ \\
I would rather talk to my doctor than Danya &
\end{tabular}

${ }^{I} N$ 's and \% reflect those that selected strongly agree or agree except for computer-animated agent the last three questions which reflect those responding strongly disagree or disagree you have things you don't want anybody else to know. Just to be able to answer and you can get a better idea." Confidentially asking questions was contrasted with preferences for having information shared with the woman's physician team, especially for those who did not have timely access to their doctor:

"A lot of us, don't know how to advocate for [ourselves]... we always forget to ask the doctor something, and to be able to do that and have the doctor see that question, and to be able to have the doctor or someone working with the doctor be able to respond to that question."The impression that the computeranimated agent could improve communication between the health care team and patient was appealing, but tempered slightly by women's concerns about privacy:

"I have mixed opinions about [Danya] because I kind of feel like it is just me and her. If it is just the two of us just talking, I feel a little bit safer... but once I report to her, who is going to transcribe all of this? If it wasn't such pertinent information, if it was just "how are you doing, we got your results back." Okay, [that's] fine, good."

Discussions about privacy and data sharing were the primary source of concerns raised by women across focus groups.

Changes in Satisfaction, Information Needs, and Knowledge. After reviewing the computer-animated agent prototype, women had greater satisfaction with the amount and quality of breast density information than before, and had greater breast density knowledge (Table 3 ). Among 24 women that had received breast density information prior to focus group participation, there was higher satisfaction with both the amount $(21 \%, n=5$ versus $67 \%, n=29 ; p<0.01)$ and quality $(17 \%, n=4$ versus $64 \%, n=27 ; p<0.01)$ of breast density information after the intervention compared to prior. In the post-intervention period, $81 \%$ respondents $(35 / 43)$ were "very satisfied" with breast density information overall (data not shown). There was no significant change in the proportion of participants with unanswered questions about breast density (pre: $67 \%, n=16$, post: $54 \%, n=13 ; p=0.37$ ), contrary to our hypothesis. This was confirmed in qualitative responses, where women indicated several areas of new questions they had not previously considered: "Her explanation leads to more questions... She said you have fatty tissue, then she used the word something else. That just raised more questions because what if we don't know what connective tissues are." Understanding the role of fatty versus connected tissue was most 
Table 3 Focus Group Pre-Post Comparison of Satisfaction, Information Needs, and Knowledge

\begin{tabular}{|c|c|c|c|}
\hline & $\begin{array}{l}\text { Pre } \\
N(\%)\end{array}$ & $\begin{array}{l}\text { Post } \\
N(\%)\end{array}$ & Sample quote \\
\hline \multicolumn{4}{|l|}{ Satisfaction $^{1}(N=24)$} \\
\hline $\begin{array}{l}\text { Satisfaction with amount of breast density } \\
\text { information* }\end{array}$ & $\begin{array}{l}5 \\
(21 \%)\end{array}$ & $\begin{array}{l}29 \\
(67 \%)\end{array}$ & $\begin{array}{l}\text { "I like the fact that she definitely said if you have any questions you can get } \\
\text { more information. We need to be able to know that we can do that because } \\
\text { it is really impossible to process all the information...that part was really } \\
\text { good." }\end{array}$ \\
\hline $\begin{array}{l}\text { Satisfaction with quality of breast density } \\
\text { information* }\end{array}$ & $\begin{array}{l}4 \\
(17 \%)\end{array}$ & $\begin{array}{l}27 \\
(64 \%)\end{array}$ & $\begin{array}{l}\text { "[Danya] did present it very well. I thought the information was right on } \\
\text { point." }\end{array}$ \\
\hline Has unanswered questions about breast density & $\begin{array}{l}16 \\
(67 \%)\end{array}$ & $\begin{array}{l}13 \\
(54 \%)\end{array}$ & $\begin{array}{l}\text { "If someone has dense breasts... how do you know it's not cancerous? } \\
\text { How do you find out?" }\end{array}$ \\
\hline \multicolumn{4}{|r|}{ 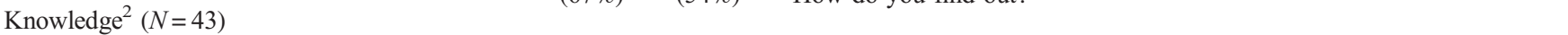 } \\
\hline $\begin{array}{l}\text { Breast density is something you or your doctor } \\
\text { can feel during an exam* }\end{array}$ & $\begin{array}{l}11 \\
(26 \%)\end{array}$ & $\begin{array}{l}23 \\
(54 \%)\end{array}$ & $\begin{array}{l}\text { "Is there any way to know without the pictures? As an older woman, when } \\
\text { gravity starts to take hold, is there any way to know the difference just from }\end{array}$ \\
\hline Breast density changes as you get older* & 34 & 24 & $\begin{array}{l}\text { the outside? Can you tell what's going on inside?" } \\
\text { "I'm in my } 50 \text { s, and I'm trying to figure out as I get older, is it going to get } \\
\text { worse -the density? GEUHAs you get older, the density is more pain, if } \\
\text { you touch it, is it more sensitive?" }\end{array}$ \\
\hline $\begin{array}{l}\text { A doctor can see how dense your breasts are } \\
\text { from looking at a mammogram }\end{array}$ & $\begin{array}{l}39 \\
(91 \%)\end{array}$ & $\begin{array}{l}41 \\
(95 \%)\end{array}$ & "From this point, I understand what density means just by looking at it." \\
\hline $\begin{array}{l}\text { Having dense breasts increases your risk for } \\
\text { cancer* }\end{array}$ & $\begin{array}{l}18 \\
(42 \%)\end{array}$ & 32 & $\begin{array}{l}\text { "I guess the whole point of this is know that you have a mammogram, } \\
\text { know that dense breasts are going to make you more likely to have cancer." }\end{array}$ \\
\hline Almost half of women have dense breasts* & $\begin{array}{l}16 \\
(37 \%)\end{array}$ & 31 & $\begin{array}{l}\text { P3: "First of all, that over half of all women have dense breasts... P5: I did } \\
\text { not know that either... P1: Yeah I thought it was less common." }\end{array}$ \\
\hline $\begin{array}{l}\text { Having dense breasts makes it harder to see } \\
\text { cancer on a mammogram* }\end{array}$ & 25 & 35 & $\begin{array}{l}\text { "I did think that picture was helpful because I did not know that dense } \\
\text { breasts looks white and the cancer looks white also. I did not know that." } \\
\text { "So I believe breast density has a lot to do with not being able to detect it } \\
\text { with just a mammogram." }\end{array}$ \\
\hline $\begin{array}{l}\text { Having dense breasts makes it easier to see } \\
\text { cancer on a mammogram* }\end{array}$ & $\begin{array}{l}23 \\
(54 \%)\end{array}$ & $\begin{array}{l}32 \\
(74 \%)\end{array}$ & No quotes represent this concept. \\
\hline $\begin{array}{l}\text { Having dense breasts may mean I should have } \\
\text { other screening tests to see if I have cancer* }\end{array}$ & 30 & 39 & $\begin{array}{l}\text { "I really appreciated the information she gave when she said you should get } \\
\text { the MRI as a second test other than the mammogram if you have dense } \\
\text { breasts... Sometimes you do not know what else to do. You do not know } \\
\text { what to ask for." }\end{array}$ \\
\hline Eating healthier will change my breast density & $\begin{array}{l}25 \\
(58 \%)\end{array}$ & $\begin{array}{l}31 \\
(72 \%)\end{array}$ & $\begin{array}{l}\text { "We talk about being obese is one of the indicators. They say you are most } \\
\text { likely to get breast cancer if you are obese? Do you talk about preventive } \\
\text { care?" }\end{array}$ \\
\hline $\begin{array}{l}\text { Having lower breast density means I will not get } \\
\text { breast cancer. }\end{array}$ & $\begin{array}{l}40 \\
(93 \%)\end{array}$ & $\begin{array}{l}39 \\
(91 \%)\end{array}$ & $\begin{array}{l}\text { "Women that get breast cancer do not always have to have dense breasts } \\
\text { right? Because I have a few friends who do not have dense breasts, who } \\
\text { have breast cancer." }\end{array}$ \\
\hline Dense breast tissue is made up of fat & $\begin{array}{l}13 \\
(30 \%)\end{array}$ & $\begin{array}{l}11 \\
(26 \%)\end{array}$ & $\begin{array}{l}\text { "What causes fatty tissues to build up in your breasts like that?" } \\
\text { "Can the fatty tissue turn into density?" }\end{array}$ \\
\hline $\begin{array}{l}\text { Most women with dense breasts will not get } \\
\text { breast cancer }\end{array}$ & $4(9 \%)$ & $(21 \%)$ & $\begin{array}{l}\text { "Just because you have dense breasts does not mean you are going to have } \\
\text { breast cancer. Complete news." }\end{array}$ \\
\hline
\end{tabular}

Asterisk indicates change is statistically significant at $\alpha=0.05$ using McNemar's test with an exact option

${ }^{I}$ Women responding "very satisfied." $N=24$ because 20 participants reported having obtained no information about breast density prior to the focus group and did not complete these questions pre-testing. Therefore, pairing was only possible for 24 participants

${ }^{2}$ Percentages of women answering correctly with data available pre-and post-intervention

difficult for women to understand based on the information presented.

Table 3 displays the percent of women who agreed with each knowledge item pre- and post-, along with representative quotes, which highlight some of the challenges in communicating about these concepts to women. The proportion of correct responses significantly increased for six of 12 true/ false knowledge questions in the post-intervention period. Women were more likely to report that having dense breasts increases risk for cancer (42 to 74\%, $p<0.01$ ), almost half of women have dense breasts ( 37 to $72 \%, p=0.02$ ), having dense breasts makes it harder to see cancer on a mammogram (58 to $81 \%, p=0.03$ ), and having dense breast may mean they should have other screening tests ( 70 to $91 \%, p=0.01$ ). More women correctly reported that breast density cannot be felt in the post-test, but the proportion remained modest (pre: $26 \%$, $n=11$, post: $54 \%, n=23 ; p<0.01)$. Women demonstrated continued confusion about whether breast density changes as they get older, dense tissue is made up of fat, or whether lower breast density means a woman will not get breast cancer.

Multi-stakeholder Acceptability Survey. Clinician $(n=5)$ and non-clinician $(n=9)$ stakeholders provided positive feedback on Danya and the education strategy (Table 4). Most reported that the agent would be easy for them or their patients to use $(79 \%, n=11)$ and understand $(86 \%, n=12)$. The most commonly endorsed uses of the computer agent were to learn information about the mammography process $(64 \%, n=9)$, or learn more about (mammogram) results $(50 \%, n=7)$. Most stakeholders felt that a patient education strategy including a computer-animated agent was better than current practice $(86 \%, n=12)$, would help them/their patients make more informed decisions $(64 \%, n=9)$, and would generate more benefit than harm $(79 \%, n=11)$. Fewer stakeholders felt that 
Table 4 Clinician $(n=5)$ and Non-clinician $(n=9)$ Stakeholder Feedback on Computer-Animated Agent

\begin{tabular}{|c|c|}
\hline & $N(\%)$ agreement \\
\hline \multicolumn{2}{|l|}{ Acceptability of the computer-animated agent } \\
\hline The amount of information provided by the computer-animated avatar was just right & $9(64 \%)$ \\
\hline The computer-animated avatar would be easy for me (my patients) to use & $11(79 \%)$ \\
\hline The information provided by the computer-animated avatar would be easy for me (my patients) to understand & $12(86 \%)$ \\
\hline \multicolumn{2}{|l|}{ I would want (my patients) to use the computer-animated avatar to: } \\
\hline Learn information about different parts of the mammography process & $9(64 \%)$ \\
\hline Learn more about my (their) results & $7(50 \%)$ \\
\hline Learn about my (their) breast cancer risk & $5(36 \%)$ \\
\hline Help reassure me (them) if they were concerned & $3(21 \%)$ \\
\hline Make a plan to reduce my (their) breast cancer risk & $3(21 \%)$ \\
\hline Remind me (them) when I (they) need their next mammogram & $5(36 \%)$ \\
\hline \multicolumn{2}{|l|}{ Acceptability of the delivery strategy } \\
\hline This strategy is better than how I (women) currently get information about breast density and breast cancer screening options & $12(86 \%)$ \\
\hline This strategy is compatible with the way I think things should be done & $11(79 \%)$ \\
\hline Compared with my usual approach, this strategy will help me (my patients) make more informed decisions & $9(64 \%)$ \\
\hline Using this strategy will save me time & $5(36 \%)$ \\
\hline Using this strategy will help me worry less ${ }^{1}$ & $4(29 \%)$ \\
\hline This type of strategy is suitable for helping me (patients) make decisions that are consistent with my (their) values & $7(50 \%)$ \\
\hline This strategy complements my usual approach ${ }^{2}$ (Pw) & $5(36 \%)$ \\
\hline This strategy does not involve making major changes to the way I usually do things & $3(21 \%)$ \\
\hline There is a high probability that using this strategy may cause/result in more benefit than harm & $11(79 \%)$ \\
\hline
\end{tabular}

${ }^{I}$ This item was only asked of non-clinical stakeholders

${ }^{2}$ This item was only asked of clinical stakeholders

the strategy would save time $(36 \%, n=5)$, or among nonclinicians only, would help them worry less $(29 \%, n=4)$.

\section{DISCUSSION}

This study tested the acceptability of a computer-animated agent prototype to deliver breast density information among a multi-stakeholder group and its impact on women's knowledge, informational needs, and satisfaction. We found that knowledge for many items improved and satisfaction was high, but some misconceptions persisted. Results of the stakeholder survey suggest initial acceptability of the prototype. Our findings point to several areas where breast density information provision can be improved for diverse populations using technology-based, interactive solutions.

Qualitative and quantitative results underscore that breast density is not an intuitive concept for many women. Most focus group participants $(75 \%)$ rated Danya as easy to understand, yet qualitative data demonstrated that women struggled to explain foundational concepts communicated in the prototype. The computer-animated agent did improve knowledge about breast density as a risk factor for cancer, with $75 \%$ of women understanding this in the post-intervention assessment. This rate is higher than other studies examining knowledge after dense breast notifications where $37-53 \%$ understand this concept after reading the notification. ${ }^{9,12,25}$ While the prototype described breast density in what is considered common terminology (i.e., the amount of fatty tissue relative to connective tissue in the breast), participants clearly had lingering questions about this definition and its meaning after a brief exposure. We will thus refine the agent to include question prompts to elicit understanding and respond with alternative explanations, clarifications, and use additional supportive images to explain breast density. The flexibility of the computer-animated agent's approach fits with data suggesting that personal relevance, context, and readiness are important considerations in learning new health concepts. ${ }^{39}$

Women highlighted that learning about mammography results, usually outside of the doctor's office, heightens anxiety when results include new terminology. Anxiety and worry have long been associated with breast cancer screening ${ }^{40-43}$ and breast density notification. ${ }^{21}$ However, interventions that comprehensively address both informational and psychosocial needs over the course of the entire screening process-from referral to diagnostic resolution-are limited. Computeranimated agents are responsive to this problem in that they deliver information on personally relevant screening topics and interact with women to provide emotional support. They have been shown to reduce anxiety, boost confidence, ${ }^{31}$ and support shared decision-making ${ }^{32}$ across health topics. Most mammography results dissemination continues to be done outside of the context of a visit, does not satisfy women's informational needs, ${ }^{44,} 45$ and is accompanied by provider reticence to comprehensively counsel on breast density, ${ }^{16-18}$ including risk assessment. ${ }^{46-49}$ The agent has the potential to effectively address these challenges that inhibit informed discussions about supplemental screening. More robust explanations about breast density and identifying when provider contact is needed may improve trust in the agent and reduce the number of individuals who reported they wanted to talk to their doctor after using the prototype, which was high at $57 \%$. We believe this primarily reflects the brevity of exposure to new content and lack of personalized information available in the current version. Future applications of this technology will incorporate personal risk assessment and integrate with the medical record so that patient confidence and clinical care 
could be improved. This study has demonstrated preliminary acceptability of this approach among a diverse set of stakeholders including clinicians, and addressing areas of modest satisfaction will enhance this prototype.

Results from the stakeholder survey indicate that this group of clinician and non-clinician professionals views the computer-animated agent as an information conduit for women; $64 \%$ endorsed the agent for providing information about mammography. Fewer supported the modality for learning about results $(50 \%)$ or learning about their risk (36\%). Given the time constraints and difficulty of using online risk calculators, which require high levels of health literacy skills to complete, ${ }^{50}$ we expected higher levels of endorsement of these activities. Yet, responses may reflect concerns about patients interacting with risk assessments without clinical guidance. These include the inherent uncertainty in risk estimates, especially in light of their modest discriminatory accuracy; the proliferation of commercial risk tools with persuasive messaging; and a lack of data on the effects of online tools for underserved populations. ${ }^{51-53}$ To achieve meaningful evidence-based decision-making for women with dense breasts, a computer-animated agent intervention must address these shortcomings of online, stand-alone tools by coordinating with health systems and providing physician support. Integration must be balanced with patient privacy concerns that were raised, underscoring the need to carefully consider where and how the computer-animated agent connects with other systems and minimize the transfer of protected health information. Optimizing these features, including integration within clinical practice and minimizing provider burden after agent interactions, will be the focus in future iterations. In addition, the fully interactive conversational agent uses fully constrained user input, enabling its advice to be completely validated (unlike chatbots and conversational assistants that use unconstrained natural language input. ${ }^{54}$

There are several limitations to this research. As a pilot study, the sample sizes across women and stakeholders are modest, limiting our explanatory power in the pre-post survey analysis. However, we see several important differences in knowledge for women, and these results are bolstered by the extensive qualitative data collection from nine focus groups. We tested the prototype in a group setting at a single time point, and we were unable to test the interactive nature of the system, which is discordant with how women will ultimately use the intervention (i.e., alone, longitudinally, and interactively). Further, we did not have sufficient sample sizes to examine stakeholder survey data by stakeholder type. We did see generally high levels of agreement across acceptability metrics, which suggests marginal utility of group comparisons, although results may be subject to some social desirability bias. Finally, our sample was predominantly black, which may not be representative of other groups' informational needs. However, the disproportionate mortality from breast cancer among black women speaks to the importance of engaging minority women in understanding their own cancer risk and evidence-based screening practices, especially given their underrepresentation in cancer control and prevention research. ${ }^{55,56}$

\section{CONCLUSIONS}

This study demonstrated initial acceptability of a computeranimated agent to deliver breast density information with a positive impact on knowledge. Findings can inform breast density education efforts in highlighting misperceptions that persisted following a brief educational exposure using commonly delivered information. Results reported by multiple stakeholders demonstrate the need for an integrated, evidence-based intervention that is easy to understand, yet maintains patient privacy. Future work should focus on how interactive interventions can be uniquely tailored to meet both the informational and psychosocial needs of women undergoing mammography across the entire diagnostic process.

Acknowledgments: The authors would like to thank members of the Pink and Black Education and Support Network in Boston, MA, for their thoughtful feedback and contribution to the design of the computer-animated agent.

Corresponding Author: Christine Gunn, PhD; Department of Medicine, Section of General Internal Medicine, Women's Health Unit, Boston University School of Medicine, 801 Massachusetts Avenue, First Floor, Boston, MA 02118, USA (e-mail: Christine.Gunn@bmc.org).

Funding Information Funding for this work was provided by the American Cancer Society (IRG-17-176-39). Dr. Gunn's effort was supported in part by the National Cancer Institute (1K07CA221899). Dr. Warner's work was supported in part by the National Cancer Institute (K01CA188075).

\section{Compliance with Ethical Standards:}

This research was reviewed and approved by the Boston Medical Center Institutional Review Board.

Conflict of Interest: The following authors have no conflicts of interest: Dr. Christine Gunn, Ms. Ariel Maschke, Dr. Timothy Bickmore, Mr. Mark Kennedy, Ms. Margaret Hopkins, Dr. Michael Paashe-Orlow, and Dr. Erica Warner. Dr. Michael Fishman is a consultant for Zebra Medical Vision and a member of the Scientific Advisory Board for Hologic.

\section{REFERENCES}

1. Sprague BL, Gangnon RE, Burt V, et al. Prevalence of Mammographically Dense Breasts in the United States. Journal of the National Cancer Institute. 2014;106(10).

2. Wang AT, Vachon CM, Brandt KR, Ghosh $\mathbf{K}$. Breast density and breast cancer risk: a practical review. Mayo Clin Proc. 2014;89(4):548-557.

3. Porter PL, El-Bastawissi AY, Mandelson MT, et al. Breast Tumor Characteristics as Predictors of Mammographic Detection: Comparison of Interval- and Screen-Detected Cancers. JNCI: Journal of the National Cancer Institute. 1999;91(23):2020-2028.

4. Mandelson MT, Oestreicher N, Porter PL, et al. Breast density as a predictor of mammographic detection: comparison of interval- and screen-detected cancers. J Natl Cancer Inst. 2000;92(13):1081-1087.

5. McCarthy AM, Keller BM, Pantalone LM, et al. Racial Differences in Quantitative Measures of Area and Volumetric Breast Density. JNCI: Journal of the National Cancer Institute. 2016;108(10):dwj 104.

6. Dense Breast Info, Inc. 2017; http://densebreast-info.org/legislation. aspx\#. 
7. Proposed Rule: Mammography Quality Standards Act. 2019; https:// www.federalregister.gov/documents/2019/03/28/2019-05803/mammography-quality-standards-act.

8. Kressin N, Gunn C, Battaglia T. Content, Readability, and Understandability of Dense Breast Notifications by State JAMA. 2016;315(16):1786-1787.

9. Rhodes DJ, Breitkopf CR, Ziegenfuss JY, Jenkins SM, Vachon CM. Awareness of Breast Density and Its Impact on Breast Cancer Detection and Risk. Journal of Clinical Oncology. 2015;33(10):1143-1150.

10. Yeh VM, Schnur JB, Margolies L, Montgomery GH. Dense breast tissue notification: impact on women's perceived risk, anxiety, and intentions for future breast cancer screening. Journal of the American College of Radiology : JACR. 2015;12(3):261-266.

11. Trinh L, Ikeda DM, Miyake KK, et al. Patient awareness of breast density and interest in supplemental screening tests: comparison of an academic facility and a county hospital. Journal of the American College of Radiology : JACR. 2015;12(3):249-255.

12. Gunn C, Battaglia T, Paasche-Orlow M, West A, Kressin N. Women's Perceptions of Dense Breast Notifications: "So what is that supposed to mean?". Patient Educ Couns. 2018;101(6):1123-1129.

13. Melnikow J, Fenton JJ, Whitlock EP, et al. Supplemental Screening for Breast Cancer in Women With Dense Breasts: A Systematic Review for the U.S. Preventive Services Task Force. Annals of Internal Medicine. 2016;164(4):268-278.

14. Freer P, Slanetz $\mathbf{P}$, Haas J, et al. Breast cancer screening in the era of density notification legislation: Summary of 2014 Massachusetts experience and suggestion of an evidence-based management algorithm by multi-disciplinary expert panel. Breast Cancer Res Treat. 2015;153(2):455-464.

15. Price ER, Hargreaves J, Lipson JA, et al. The California Breast Density Information Group: A Collaborative Response to the Issues of Breast Density, Breast Cancer Risk, and Breast Density Notification Legislation. Radiology. 2013;269(3):887-892.

16. Gunn CM, Kressin NR, Cooper K, Marturano C, Freund KM, Battaglia TA. Primary Care Provider Experience with Breast Density Legislation in Massachusetts. Journal of Women's Health. 2018;27(5):615-622.

17. Brown J, Soukas C, Lin JJ, Margolies L, Santiago-Rivas M, Jandorf L Physician Knowledge, Attitudes, and Practices Regarding Breast Density. $J$ Women's Health. 2019;28(9):1193-1199.

18. Maimone S, McDonough MD, Hines SL. Breast Density Reporting Laws and Supplemental Screening-A Survey of Referring Providers' Experiences and Understanding. Current Problems in Diagnostic Radiology. 2017;46(2):105-109.

19. Kerlikowske $\mathbf{K}$, Sprague BL, Tosteson ANA, et al. Strategies to Identify Women at High Risk of Advanced Breast Cancer During Routine Screening for Discussion of Supplemental Imaging JAMA Internal Medicine. 2019;179(9):1230-1239.

20. O'Neill SC, Leventhal KG, Scarles M, et al. Mammographic Breast Density as a Risk Factor for Breast Cancer: Awareness in a Recently Screened Clinical Sample. Women's Health Issues. 2014;24(3):e321-e326.

21. Manning M, Albrecht TL, Yilmaz-Saab Z, Shultz J, Purrington K. Influences of race and breast density on related cognitive and emotion outcomes before mandated breast density notification. Social Science \& Medicine. 2016;169:171-179.

22. Davis TC, Arnold C, Berkel H, Nandy I, Jackson RH, Glass J. Knowledge and attitude on screening mammography among low-literate, low-income women. Cancer. 1996;78(9):1912-1920.

23. Orom H, Kiviniemi MT, Shavers VL, Ross L, Underwood W, 3rd. Perceived risk for breast cancer and its relationship to mammography in Blacks, Hispanics, and Whites. Journal of behavioral medicine. 2013;36(5):466-476.

24. Pagan JA, Brown CJ, Asch DA, Armstrong K, Bastida E, Guerra C. Health literacy and breast cancer screening among Mexican American women in South Texas. Journal of cancer education : the official journal of the American Association for Cancer Education. 2012;27(1):132-137.

25. Miles RC, Lehman C, Warner E, Tuttle A, Saksena M. Patient-Reported Breast Density Awareness and Knowledge after Breast Density Legislation Passage. Acad Radiol. 2019;26(6):726-731.

26. Manning M, Purrington $\mathbf{K}$, Penner $\mathbf{L}$, Duric $\mathbf{N}$, Albrecht $\mathbf{T L}$. Between-race differences in the effects of breast density information and information about new imaging technology on breast-health decision-making. Patient Education and Counseling. 2016;99(6): 1002-1010.

27. Hunt BR, Whitman S, Hurlbert MS. Increasing Black:White disparities in breast cancer mortality in the 50 largest cities in the United States. Cancer epidemiology. 2014;38(2): 118-123.
28. Jemal A, Ward EM, Johnson CJ, et al. Annual Report to the Nation on the Status of Cancer, 1975-2014, Featuring Survival. JNCI: Journal of the National Cancer Institute. 2017; 109(9):djx030.

29. Bickmore TW, Pfeifer LM, Paasche-Orlow MK. Using computer agents to explain medical documents to patients with low health literacy. Patient education and counseling. 2009;75(3):315-320.

30. Cauell J, Bickmore T, Campbell L, Vihjalmsson H. Designing Embodied Conversational Agents. Cambridge, MA: MIT Press; 2000.

31. Olafsson S, O'Leary T, Bickmore T. Coerced Change-talk with Conversational Agents Promotes Confidence in Behavior Change. Proceedings of the 13th EAI International Conference on Pervasive Computing Technologies for Healthcare; 2019; Trento, Italy.

32. Zhang Z, Bickmore TW. Medical Shared Decision Making with a Virtual Agent. In Proceedings of Intelligent Virtual Agents. ACM; 2018; Sydney, Australia.

33. Bickmore TW, Silliman RA, Nelson K, et al. A Randomized Controlled Trial of an Automated Exercise Coach for Older Adults. Journal of the American Geriatrics Society. 2013;61(10):1676-1683.

34. Abstracts from the 2019 Annual Meeting of the Society of General Internal Medicine. Journal of General Internal Medicine. 2019;34(2):99867.

35. Gunn C, Kennedy M, Maschke A, Fishman M, Hopkins M, Warner E. Partnering with Advocates to Assess Breast Density Education Materials. Paper presented at: Society for General Internal Medicine2019; Washington, DC.

36. Harris PA, Taylor R, Thielke R, Payne J, Gonzalez N, Conde JG. Research electronic data capture (REDCap) - A metadata-driven methodology and workflow process for providing translational research informatics support. Journal of Biomedical Informatics. 2009;42(2):377-381.

37. Knafl K, Deatrick J, Gallo A, et al. The Analysis and Interpretation of Cognitive Interviews for Instrument Development. Research in Nursing and Health. 2007;30:224-234.

38. Ridolfo H, Schoua-Glusberg A. Analyzing Cognitive Interview Data Using the Constant Comparative Method of Analysis to Understand CrossCultural Patterns in Survey Data. Field Methods. 2011;23(4):420-438.

39. Bastable SB. Health professional as educator : principles of teaching and learning. Sudbury, MA: Sudbury, MA : Jones \& Bartlett Learning; 2011.

40. Consedine NS, Magai C, Krivoshekova YS, Ryzewicz L, Neugut AI. Fear, Anxiety, Worry, and Breast Cancer Screening Behavior: A Critical Review. Cancer Epidemiology Biomarkers \& Prevention. 2004;13(4):501510.

41. Watson EK, Henderson BJ, Brett J, Bankhead C, Austoker J. The psychological impact of mammographic screening on women with a family history of breast cancer-a systematic review. Psycho-Oncology. 2005; 14(11):939-948.

42. Lerman C, Trock B, Rimer BK, Jepson C, Brody D, Boyce A. Psychological side effects of breast cancer screening. Health psychology : official journal of the Division of Health Psychology, American Psychological Association. 1991;10(4):259-267.

43. Tosteson AN, Fryback DG, Hammond CS, et al. Consequences of falsepositive screening mammograms. JAMA Intern Med. 2014;174(6):954961.

44. Dolan NC, Feinglass J, Priyanath A, Haviley C, Sorensen AV, Venta LA. Measuring Satisfaction with Mammography Results Reporting. Journal of General Internal Medicine. 2001;16(3):157-162.

45. Karliner LS, Kaplan CP, Juarbe T, Pasick R, Pérez-Stable EJ. Poor Patient Comprehension of Abnormal Mammography Results. Journal of General Internal Medicine. 2005;20(5):432-437.

46. Anderson EE, Hoskins $\mathbf{K J}$. Individual Breast Cancer Risk Assessment in Underserved Populations: Integrating Empirical Bioethics and Health Disparities Research. Journal of Health Care for the Poor and Underserved. 2012;23(4):34-46.

47. Kaplan CP, Livaudais-Toman J, Tice JA, et al. A Randomized, Controlled Trial to Increase Discussion of Breast Cancer in Primary Care. Cancer Epidemiology Biomarkers \& Prevention. 2014;23(7):1245-1253.

48. Nayak L, Miyake KK, Leung JWT, et al. Impact of Breast Density Legislation on Breast Cancer Risk Assessment and Supplemental Screening: A Survey of 110 Radiology Facilities. The Breast Journal. 2016;22(5):493-500

49. Sabatino SA, McCarthy EP, Phillips RS, Burns RB. Breast cancer risk assessment and management in primary care: Provider attitudes, practices, and barriers. Cancer Detection and Prevention. 2007;31(5):375-383.

50. Cortez S, Milbrandt M, Kaphingst KA, James A, Colditz G. The readability of online breast cancer risk assessment tools. Breast Cancer Res Treat. 2015;154(1):191-199. 
51. Hesse-Biber S, Flynn B, Farrelly $\mathbf{K}$. The Pink Underside: The Commercialization of Medical Risk Assessment and Decision-Making Tools for Hereditary Breast Cancer Risk. Qualitative Health Research. 2018;28(10):1523-1538.

52. Joseph G, Beattie M, Lee R, et al. Pre-counseling Education for Low Literacy Women at Risk of Hereditary Breast and Ovarian Cancer (HBOC): Patient Experiences Using the Cancer Risk Education Intervention Tool (CREdIT). Journal of Genetic Counseling. 2010; 19:447-462.

53. Joseph-Williams N, Newcombe R, Politi M, et al. Toward minimum standards for certifying patient decision aids: A modified Delphi consensus process. Medical Decision Making. 2014;34:699-710.

54. Bickmore T, Trinh H, Olafsson S, et al. Patient and Consumer Safety Risks When Using Conversational Assistants for Medical Information: An
Observational Study of Siri, Alexa, and Google Assistant. Journal of Medical Internet Research. 2018;20(9):e11510.

55. George S, Duran N, Norris K. A Systematic Review of Barriers and Facilitators to Minority Research Participation Among African Americans, Latinos, Asian Americans, and Pacific Islanders. American Journal of Public Health. 2014;104(2):e16-e31.

56. Watts T, Merrell J, Murphy F, Williams A. Breast health information needs of women from minority ethnic groups. Journal of Advanced Nursing. 2004;47(5):526-535.

Publisher's Note Springer Nature remains neutral with regard to jurisdictional claims in published maps and institutional affiliations. 